\title{
Fabrication of texture controlled lead zirconate titanate film actuator
}

\author{
Takashi IIJIMA, Bo-Ping Zhang and Norio SANADA \\ Tohoku national Industrial Research Institute, AIST, MITI, 4-2-1 Nigatake, Miyagino-ku, Sendai \\ 983-8551, JAPAN, TEL: +81-22-237-5211, Fax: +81-22-236-6839, e-mail: iijima@tniri.go.jp \\ Kouki KUNII \\ Technical Development Dept., NIDEC COPAL CORPORATION, 37 Suwanai, Tomita, 963-8637 \\ Koriyama, JAPAN, TEL: +81-24-952-6308, FAX: +81-24-952-6375 \\ (Received 7, July 2000 Accepted 30, November 2000)
}

\begin{abstract}
A diaphragm type (100) dominant oriented tetragonal phase lead zirconate titanate (PZT) film actuator is fabricated to achieve the micro actuators and acoustic transducers system. The ferroelectric properties of the texture controlled PZT film is relatively good compared with other reported data and is comparable to those of bulk PZT ceramics. The displacement of the PZT film actuator driven at $\pm 20 \mathrm{~V}$ shows a butterfly like hysteresis. However, this butterfly shape shows opposite direction compared with the typical displacement curve of bulk PZT ceramics. This depressed displacement property of the PZT film appears to indicate bend motion in the vertical direction on the film surface since the film is not clamped, and it does not reflect the genuine piezoelectric property. The value of the maximum displacement is about $160 \mathrm{~nm}$. It can be seen that the texture controlled PZT films is applicable to the film micro actuator and transducer.
\end{abstract}

Keywords: PZT, piezoelectric, thin films, texture control, actuators

\section{INTRODUCTION}

Ferroelectric thin films including lead zirconate titanate (PZT) are in demand for applications in many fields like sensors, memories and actuators. Combination of the preparation technique for the ferroelectric films and the micro machining technique of $\mathrm{Si}$ is effective way to fabricate micro actuators for electric devices and acoustic transducers for medical devices called a micro-electric-mechanical system (MEMS) ${ }^{1-3}$ One of the techniques to increase the ferroelectric and piezoelectric properties is supposed to be arrangement of the polarization direction using a texture control process. We reported the preparation process of the (100) and (111) dominant oriented $\mathrm{Pb}\left(\mathrm{Zr}_{1-\mathrm{x}} \mathrm{Ti}_{\mathrm{x}}\right) \mathrm{O}_{3}$ thin film system using a chemical solution deposition (CSD) process. ${ }^{4}$ In this work, the preparation process of the texture controlled PZT film and the diaphragm type micro actuator fabrication process are described. Moreover, the ferroelectric properties of the PZT film are examined, and the displacement property of the diaphragm type PZT micro actuator is measured.

\section{EXPERIMENTAL PROCEDURE}

To prepare the CSD precursor solutions, we used trihydrated lead acetate (99.9\%, Nakarai tesque), titanium iso-propoxide (97\%, Kanto chemical) and zirconium iso-propoxide (98\%, AZmax) as starting materials and 2-methoxyethanol (99.7\%, Aldrich) as the solvent. The rate of $\mathrm{Zr} / \mathrm{Ti}$ was $45 / 55$, which was tetragonal phase, and excess $\mathrm{Pb}(10 \mathrm{~mol} \%)$ was 


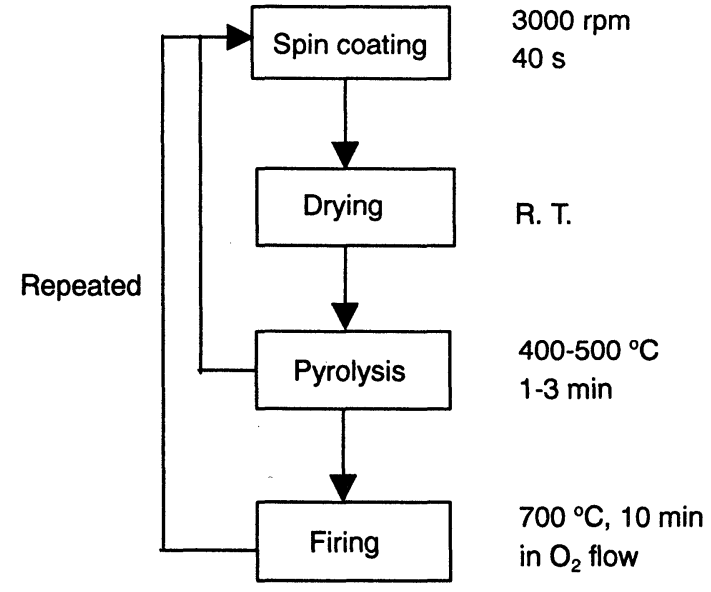

Fig. 1. Flow diagram of thin film preparation process.

added to the solution, so that the nominal compositions of the precursor solutions were equivalent to those of $\mathrm{Pb}_{1.1}\left(\mathrm{Zr}_{0.45} \mathrm{Ti}_{0.55}\right) \mathrm{O}_{3}$. Details of the preparation of the precursor solutions are described elsewhere. ${ }^{5}$ The concentration of the $\mathrm{Pb}$ $\mathrm{Zr}-\mathrm{Ti}$ precursor solution was controlled at $0.5 \mathrm{M}$. The precursor solution was deposited onto (111) oriented $\mathrm{Pt}$ on $\mathrm{Ti} / \mathrm{SiO}_{2} / \mathrm{Si}$ substrates using a spin coater operated at $3000 \mathrm{rpm}$. Before the coating process, a buck side of the $\mathrm{Pt} / \mathrm{Ti} / \mathrm{SiO}_{2} / \mathrm{Si}$ substrate was etched to form a diaphragm shape. A sequence of spin coating and pyrolysis treatment between $400^{\circ} \mathrm{C}$ and $500^{\circ} \mathrm{C}$ for $1-3 \mathrm{~min}$ was performed five times, and the samples were fired at $700^{\circ} \mathrm{C}$ for 10 min in oxygen flow atmosphere. This process was repeated several times to increase the film thickness at $1 \mu \mathrm{m}$. A flow diagram of coating process is shown in Fig. 1.

Figure 2 shows the structure of the PZT film actuator. The actuator has a $2.6 \mathrm{~mm}$ square diaphragm. To fabricate the diaphragm thermal oxidized Si wafers were etched using an anisotropic wet etching technique. After etching, Ti and Pt layer for a bottom electrode were sputter deposited onto the surfaces of the $\mathrm{SiO}_{2} / \mathrm{Si}$ substrate. PZT thin film was formed as mentioned above, and Pt layer for a top electrode was sputtered on the surfaces of the PZT film. Finally, the top electrode and the PZT layer was patterned using a wet etching process.

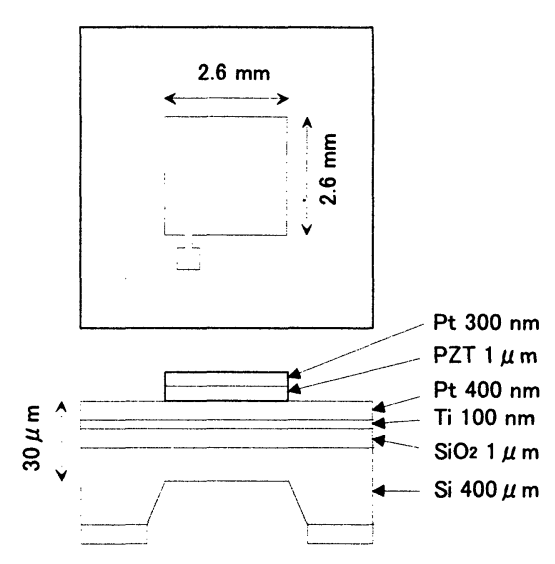

Fig. 2. Schematic diagram of diaphragm type PZT film actuator.

The crystal structure of the films was examined by an X-ray diffractometer. The $P-E$ hysteresis curves were examined using a ferroelectric test system (RT-6000, Radiant Technologies). To measure the displacement property of the actuator, a heterodyne type laser interferometer (MLD-102, Nihonkagaku Engineering) was connected with the ferroelectric test system.

\section{RESULTS AND DISCUSSION}

Figure 3 shows $X$-ray diffraction patterns of the PZT films. All patterns show a well-defined perovskite structure except for the Pt peak. When the

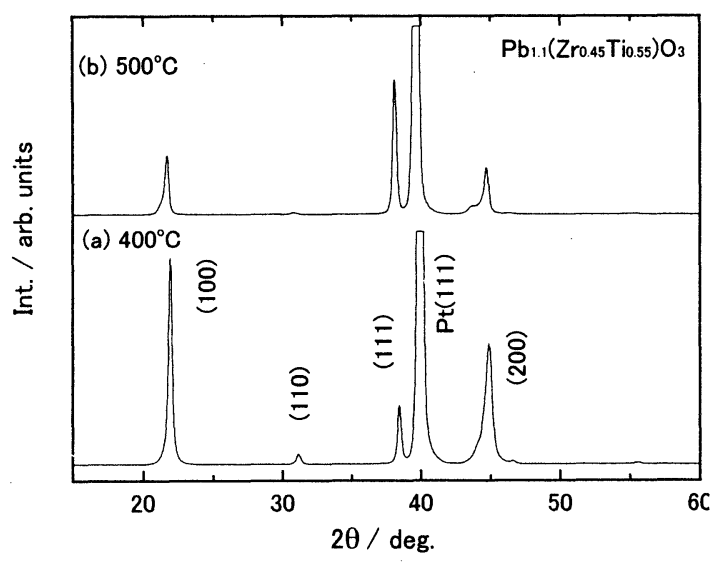

Fig. 3. XRD result of $\mathrm{Pb}_{1.1}\left(\mathrm{Zr}_{0.45} \mathrm{Ti}_{0.55}\right) \mathrm{O}_{3}$ film.

(a) Pyrolyzed at $400{ }^{\circ} \mathrm{C}$, (b) Pyrolyzed at $500^{\circ} \mathrm{C}$. 
pyrolysis temperature is $400{ }^{\circ} \mathrm{C}$, the PZT film shows (100) dominant orientation. On the other hand, the PZT film pyrolyzed at $500{ }^{\circ} \mathrm{C}$ shows (111) preferred orientation. These results are consistent with former experimental results. ${ }^{4}$ The degree of the orientation of (100) and (111) plane, $\alpha_{100}$ and $\alpha_{111}$, is calculated from the formula as follows using the peak intensity (I) of XRD.

$$
\alpha_{\mathrm{hkl}}=I(\mathrm{hkl}) /\{I(100)+I(110)+I(111)\}
$$

In the case of the PZT film pyrolyzed at $400{ }^{\circ} \mathrm{C}, \alpha_{100}$ is 0.75 , whereas $\alpha_{111}$ is 0.69 for the PZT film pyrolyzed at $500^{\circ} \mathrm{C}$.

Figure 4 shows the $P-E$ hysteresis curves of the (100) dominant oriented PZT film measured at \pm 5 and $\pm 20 \mathrm{~V}$. It can be seen that the shape of the hysteresis curve is saturated in spite of relatively low applied field $(200 \mathrm{kV} / \mathrm{cm})$. The values of the remanent polarization $(\mathrm{Pr})$ and the coercive field (Ec) are $11 \mu \mathrm{C} / \mathrm{cm}^{2}$ and $45 \mathrm{kV} / \mathrm{cm}$, respectively. Especially, the $E c$ is comparable to the value of bulk PZT ceramics, and it is relatively low compared with that of reported PZT film actuator. ${ }^{3}$ Therefore, the fabricated PZT film actuator appears to have sufficient ferroelectric properties.

Figure 5 shows the displacement property of the (100) dominant oriented PZT film actuator applied at bipolar field. When the applied voltage is $\pm 5 \mathrm{~V}$, which is lower than $E c$, the displacement property seems to vary with the applied field. However, value of the displacement is small and it is

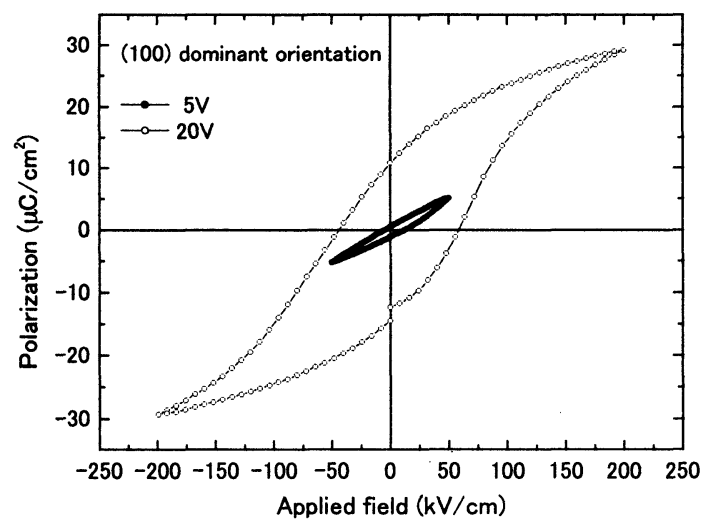

Fig.4. Ferroelectric properties of (100) dominant oriented PZT film measured at \pm 5 and $\pm 20 \mathrm{~V}$. amounted to $30 \mathrm{~nm}$. The reason of the small and linear displacement seems to be the contribution of the piezoelectric effect. On the other hand, for \pm 20 $\mathrm{V}$, which is higher than $E c$, the displacement curve is large and shows hysteresis like a butterfly shape that is typical characteristics of piezoelectric materials, since domain orientation of the PZT film occur. The value of the maximum displacement is about $160 \mathrm{~nm}$. However, this butterfly shape shows opposite direction compared with the typical displacement curve of a bulk PZT ceramics. This displacement property of the PZT film appears to indicate bend motion in the vertical direction on the film surface and does not reflect the genuine piezoelectric property. In the case of piezoelectric thin film deposited on Si substrate, ratio of the film thickness to the film surface is too low, so that magnitude of shrinkage in the surface direction is larger than that of elongation in the film thickness direction when the electric field is applied in the film thickness direction. Consequently, the thin film bends like bimorph actuator because Si buck side layer does not shrink. Moreover, the reason whey direction of the bending motion is negative, which means depression, is that the displacement property was measured without clamping the sample. If the PZT diaphragm actuator sample is free and the field is applied in the film thickness direction, the PZT surface layer shrink and center of the diaphragm bend downward. Therefore, the displacement in the film thickness direction is

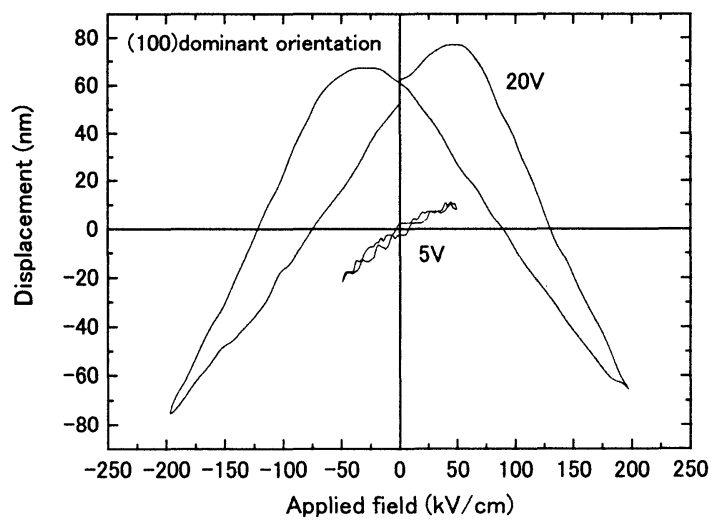

Fig. 5. Displacement property of (100) dominant oriented PZT film measured at \pm 5 and $\pm 20 \mathrm{~V}$. 
depressed ${ }^{6}$ and the displacement curve shows opposite shape ${ }^{2}$ compared with usual piezoelectricity. From these results, the (100) preferred PZT film actuator shows bending displacement property, and the film can be applicable to the micro actuators and the micro transducers.

\section{CONCLUSION}

Texture controlled $1 \mu \mathrm{m}$ - thick PZT film was deposited onto $\mathrm{Pt} / \mathrm{Ti} / \mathrm{SiO}_{2} / \mathrm{Si}$ substrate, and a diaphragm type film actuator was fabricated. The ferroelectric properties of the (100) dominant oriented PZT film were comparable to those of the bulk PZT ceramics. The $P r$ and the $E c$ at a applied voltage of $\pm 20 \mathrm{~V}$ are $11 \mu \mathrm{C} / \mathrm{cm}^{2}$ and $45 \mathrm{kV} / \mathrm{cm}$, respectively. The (100) dominant oriented PZT film showed depressed displacement property caused by bending motion. The value of the maximum displacement is about $160 \mathrm{~nm}$. It can be seen that the texture controlled PZT films is applicable to the film micro actuator and transducer. However, further investigation must be undertaken to calculate the piezoelectric coefficient like $d_{31}$ and to clear the physical properties of the PZT diaphragm actuator.

\section{AKNOWRILEDGEMENTS}

This work was partially supported by Researches on Artificial Materials for the Next Generation (RFTF96P00105) from the Japan Society for the Promotion of Science and Regional Consortium Project (NEDO). The authors would like to thank Mr. Y. Hayashi for experimental assistance in this work.

\section{REFERENCES}

${ }^{1}$ H. D. Chen, K. R. Udayakumar, L. E. Cross, J. J. Bernstein and L. C. Niles, J. Appl. Phys. 77, 3349 (1995).

${ }^{2}$ S. Wakabayashi, M. Sakata, H. Goto, M. Takeuchi and T. Yada, Jpn. J. Appl. Phys. 35, 5012 (1996).

${ }^{3}$ I. Kanno, S. Fujii, T. Kamada and R. Takayama, Appl. Phys. Lett. 70, 1378 (1997).

${ }^{4}$ Takashi Iijima, Toshihiko Abe and Norio Sanada, Proc. of The 9th US-Japan Seminar on Dielectric and Piezoelectric Ceramics (1999), pp. 215-218.

${ }^{5}$ T. Iijima, N. Sanada, K. Hiyama, H. Tsuboi and M. Okada: to be published in Mater. Res. Soc. Symp. Proc., Ferroelectric Thin Films VII (1999).

${ }^{6}$ A. L. Kholkin, Ch. Wuetchrich, D. V. Taylor and N. Setter, Rev. Sci. Instrum. 67, 1935 (1996)

Presented at 3rd Japan France Seminar on IMS 